4 Sinead Rocha*, Adam Attaheri, Aine Ni Choisdealbha, Perrine Brusini, Sheila Flanagan,

5 Natasha Mead, Panagiotis Boutris, Samuel Gibbon, Helen Olawole-Scott, Christina Grey, 6 7 8

Infant sensorimotor synchronisation to speech and non-speech rhythms:

\section{A longitudinal study} Isabel Williams, Henna Ahmed, Emma Macrae \& Usha Goswami

$$
\text { *sineadrocha@gmail.com }
$$


Abstract

10 Impaired sensorimotor synchronisation (SMS) to acoustic rhythm may be a marker of atypical language development. Here, Motion Capture was used to assess gross motor rhythmic movement at six timepoints between five- and 11-months-of-age. Infants were recorded drumming to acoustic stimuli of varying linguistic and temporal complexity: drumbeats, repeated syllables and nursery rhymes. Longitudinal analyses revealed that whilst infants could not yet reliably synchronise their movement to auditory rhythms, infant spontaneous motor tempo became faster with age, and by 11 -months, a subset of infants were able to decelerate from their spontaneous motor tempo, to better accord with the incoming tempo. Further, infants became more regular drummers with age, with marked decreases in the variability of spontaneous motor tempo and variability in response to drumbeats. This latter effect was subdued in response to linguistic stimuli. The current work lays the foundation for using individual differences in SMS in infancy to predict later language outcomes. 
The ability to generate motor rhythms and couple them to external rhythms underlies many important features of our species, including social interaction, music, dance, and critically, language. The core role of rhythm in language development is captured by the Temporal Sampling framework (TSF, Goswami, 2011, 2018). The TSF proposes that accurate sensory/neural tracking of the slow rhythm patterns in the speech amplitude envelope is a key factor in language development, and that children with disorders of language development will show atypical cortical tracking. Behaviourally, rhythm tracking can be indexed by impaired sensorimotor synchronisation (SMS) to slower beat rates, particularly $\sim 2 \mathrm{~Hz}, 120$ beats per minute (Cumming et al., 2015).

Through childhood, reduced accuracy and greater variability in SMS is linked to poor language outcomes. In typically-developing three- to four-year-olds, less accurate synchronisation is associated with poor pre-reading skills (Woodruff Carr et al., 2014, Politimou, et al., 2019; Rios-Lopez, Molinaro, \& Lallier, 2019). Children with dyslexia show less accurate SMS than typically developing peers, (Thomson \& Goswami, 2008; Lee et al., 2015; Persici et al., 2019), and SMS is correlated with their language outcomes (Overy et al., 2003; Flaugnacco et al., 2014), over and above general motor dexterity (Thomson \& Goswami, 2008). Similar patterns are evident in developmental language disorder (DLD; Corriveau \& Goswami, 2009; Cumming et al., 2015), and in children who stutter (Falk et al., 2015; Olander et al., 2010). Recently, this converging evidence has led to an Atypical Rhythm Risk Hypothesis (ARRH; Ladanyi et al., 2020), which contends that impaired SMS, in addition to perceptual timing difficulties, can identify children at risk of speech and language disorders. SMS is a strong candidate for a simple behavioural risk marker of disordered language acquisition (Lundetrae \& Thomson, 2018) and may also provide a route for remediation, helping mitigate the considerable life-long costs of language disorders. For example, preschool music interventions enhance phonological awareness (Dege \& Schwarzer, 2011; Linnavalli et al., 2018), and children with more variable baseline SMS benefit most from rhythmic movement interventions (Bhide, et al., 2013). 
The typical development of SMS is protracted, improving into adulthood (Drake et al., 2000; Thompson et al., 2015). SMS is not reliably seen in children until around 2.5 years (Kirschner \& Tomasello, 2009), although case studies show the beginnings of SMS as young as three-four months-of-age (Fujii et al., 2014). SMS is preceded by tempo-flexibility, namely moving faster to faster auditory tempi and slower to slower tempi (Zentner \& Eerola, 2010). Spontaneous rhythmic movements are elicited equally by simple isochronous drumbeats and naturalistic music, and generally more to musical stimuli than to naturalistic adult- and infant-directed speech (Zentner \& Eerola, 2010). Critically, very young (three to four-monthold) infants tend to move more in silence than to music (Fujii et al., 2014), and six- to 10month-olds move equally in silence as to music (de l'Etoile et al., 2020). Early repetitive motor movements, in which infants can spend $40 \%$ of their time, have been described as stereotypies, reflexive or rhythmic actions that precede deliberately-controlled movement (Thelen, 1981). Establishing infants' natural rate of rhythmic movement in the absence of stimulation (Spontaneous Motor Tempo; SMT) is therefore critical for understanding the development of SMS. Indeed, toddlers and children are only able to achieve SMS to tempi close to their SMT (Bobin-Begue \& Provasi, 2008). Newborns (Bobin-Begue et al., 2006), toddlers (Bobin-Begue \& Provasi, 2008) and children (McAuley et al., 2006) also demonstrate clear difficulties in deceleration compared to acceleration.

Infant SMT, as measured via a free drumming task, becomes faster and less variable with age, presumably in line with development of motor control (Rocha, Southgate \& Mareschal, 2021). Rocha et al (2021) reported an SMT of drumming close to $2 \mathrm{~Hz}(542 \mathrm{~ms}$ Inter-Onset-Interval; IOI) for infants with a mean age of 11 months. This is notable, as during language acquisition the presence of stressed syllables in the speech signal at approximately $2 \mathrm{~Hz}$ intervals may provide a skeletal beat-based structure upon which human language processing builds (Cumming et al., 2015). Similar intonational patterns (stressed syllables approximately every $500 \mathrm{~ms}$ ) are evident across languages (Dauer, 1983), and are carried by slow amplitude modulations in the speech envelope (Leong et al., 2017). The beat 
rate of lullabies sung to infants across cultures is also $2 \mathrm{~Hz}$ (Trehub \& Thorpe, 1989), and amplitude modulations focused around $2 \mathrm{~Hz}$ are heightened in infant-directed speech (IDS; Leong et al., 2017). By the TSF, individual differences in infant drumming at a $2 \mathrm{~Hz}$ rate could thus predict later language outcomes. Accordingly, repeated measurements of infant rhythm production can provide nuanced understanding of the pathway(s) towards infant SMS, and potentially, language acquisition.

To date, the development of SMS with different types of linguistic and musical stimuli in the same infants has not been studied. Further, existing studies do not consider the development of SMS in relation to infants' own SMT. The BabyRhythm project is a longitudinal study of 122 infants from two- to 30-months-of-age, investigating neural entrainment and SMS to acoustic rhythm in relation to typical language development. Gross motor rhythmic movement was measured using motion capture at six timepoints between five- and 11-months-of-age. Infants were recorded drumming to stimuli of increasing linguistic and temporal complexity: Silence ('Spontaneous Motor Tempo'; SMT), a 2 Hz (500 ms IOI) fixed rate drum beat ('Drum'), a 2 Hz repetition of the syllable 'ta' ('Syllable'), and infant directed songs of varying tempi from $1-2.33 \mathrm{~Hz}$ ('Nursery Rhymes'). In the current paper we track the typical development of infant SMS to speech and non-speech rhythmic sounds over the first year of life. We hypothesise that infant drumming will i) become faster and more regular with age, ii) will better match the tempo of rhythmic stimuli with age, and iii) will more accurately match the tempo of the simpler rhythmic stimuli.

\section{Methods}

Participants

Infants ( $N=122,57$ female) were recruited for the longitudinal Cambridge UK BabyRhythm Project. Families were recruited from the local area via flyers and online advertisements, forming a sample of convenience. At laboratory visits at five, six, seven, eight, nine and 
eleven months, infants first took part in an EEG testing session (see Attaheri et al., 2022), followed by the motion capture testing session detailed here. Table S1 provides details of infants contributing at each timepoint (5-month $N=65,6$-month $N=67$, 7-month $N=68$, 8month $\mathrm{N}=74$, 9-month $\mathrm{N}=82,11$-month $\mathrm{N}=87$ ); the full sample were not tested on this paradigm for reasons given below. First, unanticipated building work meant some sessions had to be conducted on a different site without motion capture technology, so infants only took part in the EEG paradigms (5-month $N=16,6$-month $N=21$, 7-month $N=14$, 8-month $N=9,9$-month $N=5$ ). Second, whilst the EEG protocol was finalised before the wider BabyRhythm project commenced, the motion capture protocol took much longer to be finalised, and due to the longitudinal design of the project, this meant that some motion capture sessions are categorised as 'pilots', despite the infants' membership in the final sample. The pilot phase did not produce comparable data - the baseline SMT condition did not always occur or occur first, the infant did not always have access to a drum, trial lengths were not set, the experimenter in the room did not follow a strict protocol of allowable prompts, and critically, recording thresholds were incorrectly applied, such that other objects in the recording space were detected by the system and many false datapoints were introduced. Data recorded under these conditions have not been processed or analysed, and whilst videos of these sessions are available, they are not presented here (5-month $\mathrm{N}=$ 27, 6-month $\mathrm{N}=19,7$-month $\mathrm{N}=18$, 8-month $\mathrm{N}=22$, 9-month $\mathrm{N}=20,11$-month $\mathrm{N}=22$ ). Finally, some sessions were not attempted on the day or were terminated without data due to infant fussiness or technical failure (5-month $N=14,6$-month $N=15,7$-month $N=17,8$ month $\mathrm{N}=13,9$-month $\mathrm{N}=11,11$-month $\mathrm{N}=12$ ). The study was approved by the University of Cambridge ethics committee. The caregiver gave written, informed consent concerning the experimental procedure. Infants received a certificate and small age appropriate gift as a thank you for participation (e.g. book, teething toy), and any travel expenses incurred were refunded to the caregiver. 
131

132

Procedure

Rigid body arrays of three to four $10 \mathrm{~mm}$ diameter spherical markers were attached via elastic and Velcro straps onto the infant's wrists, ankles, and head. The infant was loosely strapped into an adapted highchair, and a 12-inch tuneable wood shell and natural skin head drum was secured to the arms of the highchair using clamps, such that the drum formed a 'table' in easy reach of the infant (see Figure S1). The infant was facing an LCD screen 2 meters away with speakers placed either side. The caregiver sat adjacent to and slightly behind the infant, approximately one meter away. An experimenter sat adjacent to and slightly in front of the infant, holding a separate drum. The infant took part in four conditions (SMT, Drum, Syllable, and Nursery Rhymes). The baseline SMT condition was always presented first, followed by counterbalanced presentation of the three experimental conditions. Each condition block consisted of eight individual trials.

During the SMT trials the experimenter demonstrated that the infant's drum made a sound by hitting the drum once, and talking to the infant to draw their attention to the drum. Single drum hits by the experimenter were repeated as necessary during the trial, with a minimum interval of 2 seconds between prompts to ensure no rhythmic example was provided.

In the Drum condition the screen and speakers facing the infant presented 8 audiovisual trials of a hand hitting a drum at $2 \mathrm{~Hz}(500 \mathrm{~ms} \mathrm{IOI})$. During the first trial, and then alternating subsequent trials, the experimenter drummed along with the stimuli on their own small bongo drum, such that there were four 'social' trials, and four 'non-social' trials where the experimenter remained present and engaged with the infant but did not produce rhythmic actions in time with the stimuli. Each trial consisted of 16 seconds of stimuli appended by four seconds of silence. The Syllable condition was conducted in the same manner, except that the stimuli were eight trials of an audio-visual presentation of a female repeating the syllable 'ta' at $2 \mathrm{~Hz}$, and the experimenter spoke along with the video during the social trials. 
157 The Nursery Rhyme condition was similar, except that each trial presented a different

158 Nursery Rhyme verse (see Table S2), which varied in tempo (range $=430 \mathrm{~ms} \mathrm{IOI}-1000$

$159 \mathrm{~ms} \mathrm{IOI}, \mathrm{M}=636 \mathrm{~ms} \mathrm{IOI})$. The experimenter sang along with the rhymes during the social

160 trials. During all trials, if the infant was not engaged the experimenter would repeat a single

161 hit of the infant's drum to encourage a response. If infants became fussy, the experimenter

162 moved to the next block, or terminated the experiment.

164 Apparatus

Kinematic data were recorded using a Vicon system. Six to eight Vicon Vero version 1.3 cameras (two cameras were unreliable and offline for some periods of data collection) provided 360-degree coverage of the testing space, and data were captured at a frame rate of $200 \mathrm{~Hz}$ using Vicon Tracker (Versions 3.4-3.7). Video stimuli were presented using a custom script in PsychoPy (Peirce et al., 2019), at a comfortable volume, $65 \mathrm{~dB}$. Responses were time locked to the stimuli using audio triggers recorded via the Vicon Lockbox. Simultaneous video recording of the testing session was conducted using a Logitech C525 webcam positioned on top of the presentation screen, with a $27.75 \mathrm{~Hz}$ frame rate, and audio was recorded at a sampling rate of $48000 \mathrm{kHz}$ using a RS Pro Lavalier Wired Microphone lapel microphone clipped to the infant highchair.

Data Processing

177 Coordinates of infant movement across all recorded markers were processed using the Motion Capture Toolbox (MCT; Burger \& Toiviainen, 2013), in Matlab (MATLAB R2017b; The MathWorks Inc.). Missing frames were filled using the 'mcfillgaps' function, which uses linear interpolation. For each trial, markers corresponding to the infants' right and left wrists were selected and a windowed enhanced autocorrelation was performed using the 
'mcwindow' and 'mcperiod' functions, with a 2 second window length and 1 second window hop. The maximum enhanced autocorrelation value for z-axis (vertical plane) was taken as the dependent variable Regularity. The periodicity (tempo) of z-axis movement corresponding to this maximal autocorrelation value was extracted, and the mean periodicity across trials used as the dependent variable Periodicity. A custom MATLAB script filtered out trials where the maximum enhanced autocorrelation value was less than .01 (to remove noise), and/or gave corresponding periodicities of less than $100 \mathrm{~ms}$ (to remove noise and rapid periods) or more than $1500 \mathrm{~ms}$ (to remove slow oscillations), then selected the infants' highest autocorrelation value on each trial from left and right wrists. Mismatch scores were calculated as the difference between the periodicity produced and the target periodicity of each trial. For the SMT trials where no target periodicity was expected, $500 \mathrm{~ms}$ (equating to a $2 \mathrm{~Hz}$ rhythm) was used as the 'target' in order to later test whether infant tempo matching to $2 \mathrm{~Hz}$ targets in test trials differed from their baseline performance. Data were exported to $R$ (version 4.0.0, R Core Team, 2021) for analysis.

Video coding was also conducted for a subsample of infants $(N=13,5$-month $N=7$, 6-month $\mathrm{N}=7$, 7-month $\mathrm{N}=5$, 8-month $\mathrm{N}=10$, 9-month $\mathrm{N}=11,11$-month $\mathrm{N}=8$ ). Type and frequency of repetitive movements (two or more movements occurring on the same plane, with less than 2 seconds between movements) were annotated by a naïve coder using ELAN (Version 6.0; Sloetjes \& Wittenburg, 2008). Table S3 describes the video coding scheme. Annotations started one frame before movements started and ended in the first frame of resting state following the movement. The number of actions performed, as well as the duration of the movement series, were recorded. Infants could perform multiple repetitive actions at the same time (e.g. drumming and nodding head). The duration of vocalisations were also annotated. Data were excluded when the infant became very fussy, was out of view of the camera, or where the parent/experimenter made contact with the infant (e.g. to adjust posture, reposition markers), and could therefore influence their movement. Data were managed using REDCap electronic data capture tools (Harris et al., 2009). 


\section{Results}

211 Tempo Mismatch

212 Figure 1A shows the tempo mismatch of infant drumming (difference from periodicity of

213 infant drumming to target periodicity) at each timepoint (age), in each condition. Tempo

214 mismatch in the silent SMT condition refers to mismatch from a non-existent $500 \mathrm{~ms} / 2 \mathrm{~Hz}$

215 tempo for comparison with experimental conditions. A mismatch closer to zero in the

216 experimental conditions indicates more accurate performance. Table 1 displays the means

217 and standard deviations for each timepoint by condition. It appears that performance

218 becomes more accurate with age in the Drum and Syllable conditions, but a relatively stable

219 pattern/ less accurate drumming with age appears to characterise Nursery Rhyme condition.

220 Tempo mismatch closer to zero with age in the SMT condition reflects infant drumming

221 becoming closer to a $2 \mathrm{~Hz}$ tempo in the absence of any stimuli.

Table 1: Tempo mismatch scores (milliseconds) by age and condition

\begin{tabular}{lllll}
\hline Age & SMT $(M(S D))$ & Drum $(M(S D))$ & Syllable $(M(S D))$ & Nursery Rhyme $(M(S D))$ \\
\hline 5 & $277(95)$ & $278(76)$ & $264(98)$ & $297(160)$ \\
6 & $181(93)$ & $226(100)$ & $214(126)$ & $292(110)$ \\
7 & $172(96)$ & $209(96)$ & $206(120)$ & $296(111)$ \\
8 & $155(82)$ & $206(89)$ & $202(114)$ & $309(99)$ \\
9 & $155(100)$ & $202(97)$ & $205(103)$ & $326(109)$ \\
11 & $169(98)$ & $196(83)$ & $213(106)$ & $332(132)$ \\
\hline
\end{tabular}


2013). Tempo mismatch was included as the dependent variable. Predictor variables included the within-participants factors condition (SMT, Drum, Syllable, Nursery Rhymes), and timepoint $(5,6,7,8,9$ \& 11 months $)$ and the timepoint ${ }^{*}$ condition interaction. Random intercepts were included for subjects, and correlated random slopes for timepoint. The model specification was as follows: 'tempo mismatch $\sim$ condition * timepoint $+(1+$ timepoint|subject)'. SMT was used as the base case. Significance was calculated using the ImerTest package (Kuznetsova, Brockhoff, \& Christensen, 2017), which applies

Satterthwaite's method to estimate degrees of freedom and generate $p$-values for mixed models.

This analysis indicated a significant main effect of timepoint, such that infants reduce their tempo mismatch with age $(F(5,107)=7.62, p<.001)$, a significant main effect of condition $(F(3,1235)=119.69, p<.001)$, and an age ${ }^{*}$ condition interaction $(F(15,1227)=$ $4.13, p<.001)$, largely reflecting that tempo mismatch increased with age in the Nursery Rhyme condition, see Table S4 for all coefficients.

\section{Periodicity}

Given that in the absence of stimulation (SMT condition), infants seem to show a similar pattern of 'mismatch' as during the Drum and Syllable conditions, it is possible that the age effects reported for tempo mismatch above reflect the general trend for infants to move more quickly as they get older. In Figure 1B, the mean periodicity of infant movement is plotted in seconds for each condition at each timepoint. A linear mixed-effects model with the same structure as above (specification: 'periodicity condition * timepoint $+(1+$ timepoint|subject'), shows a main effect of timepoint $(F(5,87)=5.39, p<.001)$, see table S4 all coefficients). There is also a marginal main effect of condition $(F(3,1170)=2.61, p=.05))$, but no timepoint*condition interaction. Overall, infants are drumming at a faster tempo as they get older (5-month SMT = $655 \mathrm{~ms}, 11$-month SMT $=530 \mathrm{~ms})$. Though the full interaction term is 
253

254

255

256

257

258

259

260

261

262

263

264

265

266

267

268

269

270

271

not significant, it appears that by 11-months, infants are drumming more slowly in the Nursery Rhyme condition ( $\beta=87.56, t=2.80, p=.005$; full means in Table 2 , coefficients in Table S4). Whilst at 5-months infants show roughly the same periodicity in the Nursery Rhyme condition as in silence, by 11 -months infants are decelerating the tempo of their drumming (demonstrating a longer $\mathrm{IOI}$ ) in response to the Nursery Rhyme stimuli, as depicted in Figure 2, and Table S3. To directly test this pattern, we classified Nursery Rhymes as Fast $(\sim 2 \mathrm{~Hz})$ or Slow $(1 \mathrm{~Hz})$. We ran Bayesian one-sided paired-sample t-tests to demonstrate the strength of evidence for the hypothesis of slower drumming to Slow Nursery Rhymes than in silence, over the null hypothesis of no difference. $\mathrm{BF}_{10}>3$ indicate moderate evidence for a difference between conditions, and $\mathrm{BF}_{10}>10$ indicate strong evidence for a difference. At 11-months, there is indeed strong evidence for slower drumming to the Slow Nursery Rhymes (Slow $\mathrm{M}=604 \mathrm{~ms}, \mathrm{SMT} M=530 \mathrm{~ms} ; \mathrm{t}(61)=-2.93, p=.002, \mathrm{BF}_{10}=13.24$ ). This can be contrasted with the infants' performance at 5-months (Slow M $=682 \mathrm{~ms}$, SMT = $655 \mathrm{~ms},(\mathrm{t}(45)=-.934, \mathrm{p}=.178, \mathrm{BF} 10=.393$, a non-significant difference with anecdotal evidence for the null hypothesis. Intriguingly, Figure 2 shows a bimodal distribution, suggesting that a sub-group of infants are driving the pattern of deceleration, a point we expand upon in the discussion.

Table 2: Periodicity (milliseconds) by age and condition

\begin{tabular}{lllll}
\hline Age & SMT (M(SD)) & Drum (M(SD)) & Syllable (M(SD)) & Nursery Rhyme (M(SD)) \\
\hline 5 & $655(152)$ & $648(174)$ & $655(168)$ & $633(199)$ \\
6 & $597(112)$ & $610(167)$ & $582(173)$ & $599(134)$ \\
7 & $553(116)$ & $552(148)$ & $565(174)$ & $578(146)$ \\
8 & $526(133)$ & $544(154)$ & $548(148)$ & $560(141)$ \\
9 & $534(119)$ & $549(164)$ & $556(146)$ & $576(170)$ \\
11 & $530(137)$ & $533(137)$ & $551(171)$ & $587(187)$ \\
\hline
\end{tabular}


273 Regularity

274 We predicted that infants would become more regular drummers with age. To test this

275 hypothesis, we took the maximum enhanced autocorrelation value (reflecting infants' best

276 performance in each condition; where 0 indicates no relationship, and 1 indicates a perfect

277 relationship between the z-axis coordinates over a two second moving window), to index the

278 dependent variable Regularity. Figure 1D shows a pattern of higher autocorrelation values at

279 the later timepoints. This relationship was supported by a further linear mixed effect model

280 with Regularity as the dependent variable, and the same structure as the models above

281 (specification: 'regularity condition *timepoint $+(1+$ timepoint|subject)'), which reveals a

282 significant main effect of timepoint $(F(5,74)=20.92, p<.001)$. We also find a significant

283 effect of condition $(F(3,1136)=24.92, p<.001)$, where regularity is greatest during

284 spontaneous drumming, and a significant timepoint ${ }^{*}$ condition interaction $(F(15,1128)=3.63$,

$285 p<.001)$. Inspection of the interaction revealed that whilst infants generally became more

286 regular (less variable) with age, the increase in regularity was significantly smaller in the

287 Nursery Rhyme condition at 9 -months $(\beta=-0.04, p=.046)$, and 11-months $(\beta=-0.07, p<$

$288.001)$, a trend also seen in the Syllable condition at 11 -months $(\beta=-0.04, p=.050)$.

Periodicity and Regularity

These analyses suggest that the Nursery Rhyme condition induces different rhythmic behaviours than the $2 \mathrm{~Hz}$ experimental conditions: at later timepoints infants seem to be both decelerating their drumming from their SMT and producing more variable drumming.

Accordingly, we investigated whether periodicity and regularity of drumming was related within infants attempting to tempo-match. Figure 1E illustrates the relationship between regularity and periodicity in the Nursery Rhyme condition at each timepoint. Exploratory 
297 correlations show that whilst we do not find evidence of a linear relationship between rate of 298 movement and the regularity of that movement at 5-months-of-age $(r=-.029, t(54)=-.22, p$ $299=.829)$, at 11-months infants drumming at a slower tempo show significantly less regularity $300(r=-.317, t(68)=-2.75, p=.008)$. However, a regression utilising data from all timepoints 301 (specification: regularity periodicity + periodicity $^{2}$ ) suggests an overarching quadratic 302 relationship. We see a positive relationship between regularity and periodicity, suggesting 303 that infants who were drumming more slowly to the nursery rhymes were also drumming 304 more regularly $(\beta=0.0004, \mathrm{t}(391)=3.021, p=.003)$, but a negative binomial coefficient $(\beta=$ $305-0.0000004, \mathrm{t}(391)=-4.208, p<.001 ; \mathrm{F}(2,391)=18.85, p<.001)$, suggesting that infants 306 who were drumming very slowly were also drumming irregularly. 

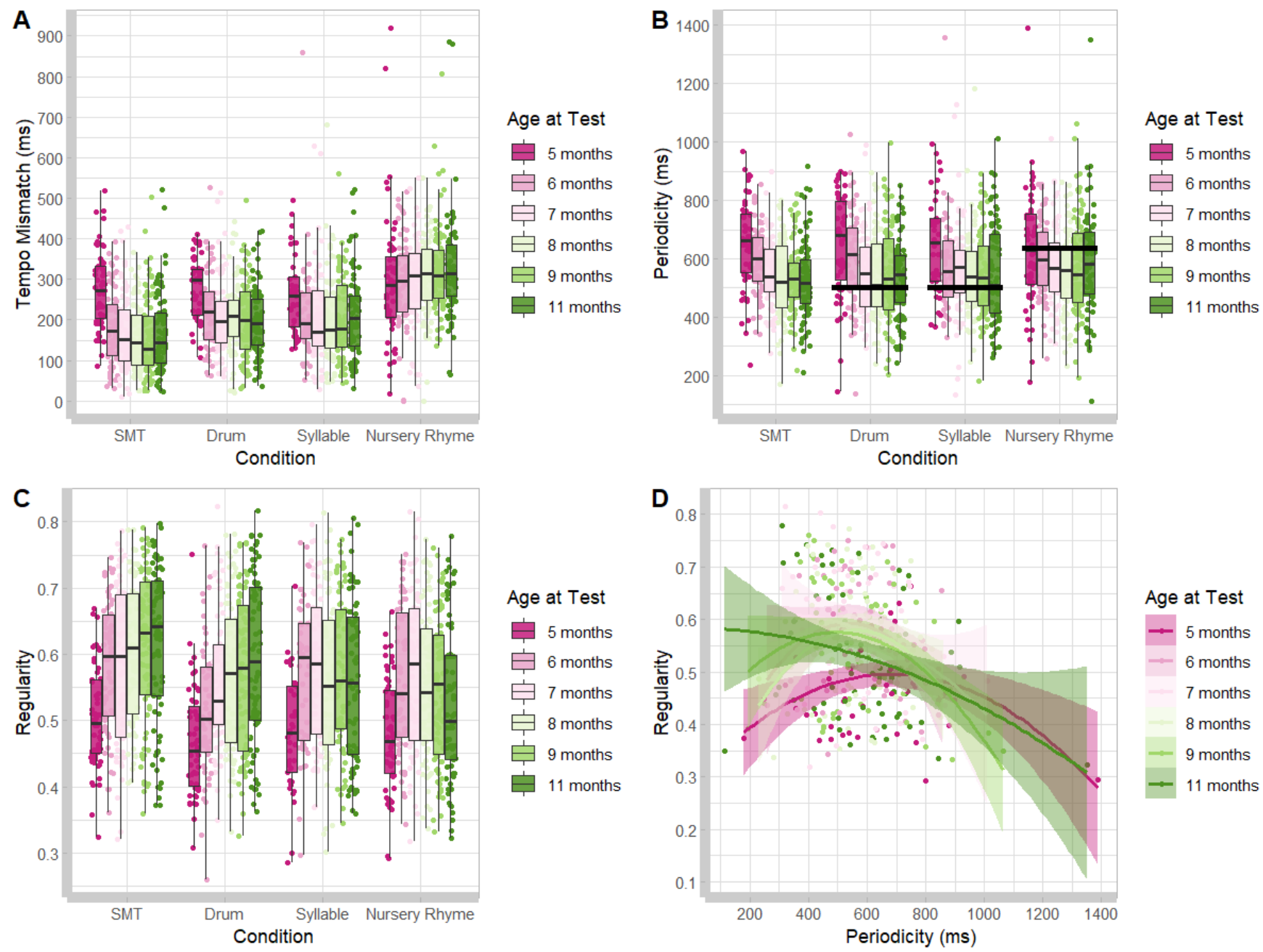

Figure 1. Box plots and jittered raw data, for each condition, and across age, for A) infant tempo mismatch (difference in periodicity of drumming from the target rate of stimuli), B) Periodicity of drumming in seconds, and C) Regularity of infant drumming as indexed by their maximum enhanced autocorrelation score (0-1). Note that in A, there was not a target rate for infant drumming in the SMT condition, and an artificial $2 \mathrm{~Hz}$ (500 ms IOI) target rate has been imposed for comparability across conditions. Horizontal lines in B show the mean target IOI for each experimental condition (no target IOI for baseline SMT condition). Figure 1D. Scatterplot shows the raw data, and polynomial (second order) regression lines with $95 \% \mathrm{Cl}$, of the relationship between regularity and periodicity of infant drumming in the Nursery Rhyme condition at each timepoint. 

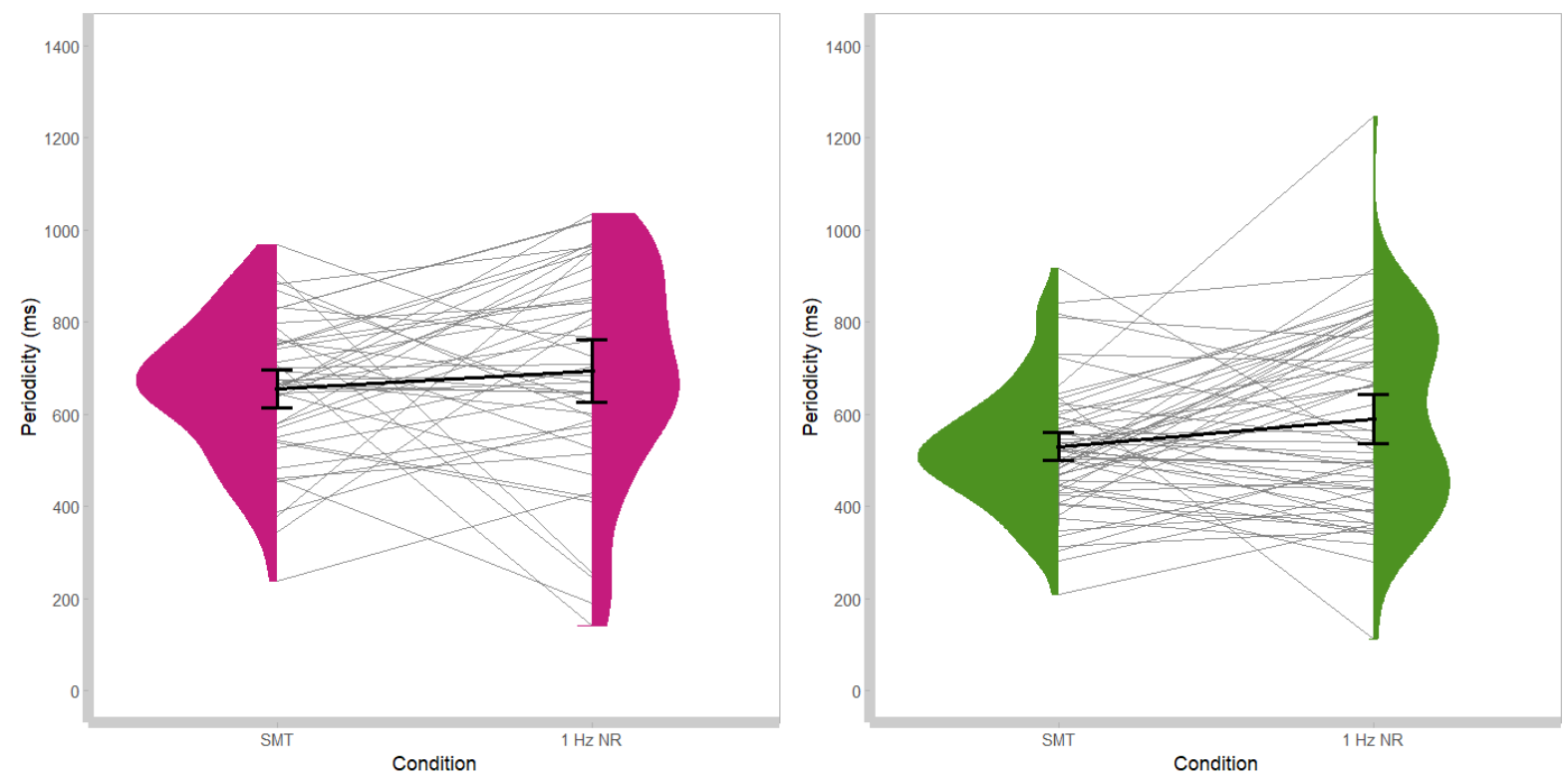

Figure 2. Periodicity of infant drumming during silence (SMT) and Slow (1 Hz) Nursery Rhymes, at 5months (left, pink) and 11-months (right, green). Group level Means and $\mathrm{Cl}$ are shown in bold, and individual data points are connected. Half violins show the distribution of results. 
Type and frequency of rhythmic movements

Finally, whilst the focus of our analyses thus far has been on infant drumming as a potential future marker of language acquisition, here we present a general description of infant rhythmic behaviour, across effectors, that were exhibited in response to our stimuli. Video, rather than motion capture data, are used for this purpose, to code a wide range of motions (see Table S3 for coding scheme). A pseudo-randomly selected subsample of infants' videos (infants chosen who had multiple recordings; $N=13,5$-month $N=7,6$-month $N=7$, 7-month $\mathrm{N}=5,8$-month $\mathrm{N}=10,9$-month $\mathrm{N}=11,11$-month $\mathrm{N}=8$ ) were manually coded for the type, number and duration of repetitive movements according to the coding scheme (Table S3), and duration of vocalisations. On average, infants spent $26 \%$ of the trial duration performing repetitive movements. Drumming was prominent, but a variety of movements were seen at all ages, with rhythmic sucking and circling of the ankles particularly notable (see Figure 3A). Note that movements could take place concurrently across the body.

Infants engaged in more repetitive movements in the first SMT condition than in the subsequent experimental conditions $(\mathrm{SMT} M=.377, \mathrm{SD}=.163$, Drum $\mathrm{M}=.225, \mathrm{SD}=.140$, Syllable $M=.273, S D=.163$, Nursery Rhyme $M=.233, S D=.137$; see Figure $3 B$ ), suggesting that they attended to the acoustic stimuli. Frequentist and Bayesian repeated measure ANOVAs with post hoc tests revealed a strong effect of condition ( $F=13.106, p<$ .001), which was driven by more rhythmic movement in silence than during stimulation (all $p$ $<.001$; all $\mathrm{BF}_{10}>39$ ), and no difference between experimental conditions (all $p>.483$; all BF $<1$; Drum and NR comparison $\left.p=1.00, \mathrm{BF}_{10}=.181\right)$. Importantly, this suggests that differences in tempo matching/regularity found in the Nursery Rhyme condition are not due to a different level of participation. Further, infants were also moving for an equal proportion of the fast and slow nursery rhymes, with a Bayesian paired t-test confirming good evidence for no difference in proportion of time spent moving between the fast NR $(M=.235)$ and slow $\mathrm{NR}(\mathrm{M}=.213)$ conditions, $\mathrm{BF}_{10}=.235$; see Figure $3 \mathrm{C}$. 
In pilot testing, we observed that some infants moved more when they had an

interactive partner drumming or singing with them, but that some infants were more inhibited

when the partner joined in. We therefore alternated trials where the partner was

drumming/singing and not drumming/singing, throughout all experimental conditions (i.e. not

infants spent a higher proportion of time in rhythmic movement when the partner was not

340 drumming/singing $(M=.285, S D=.138)$ than when they were $(M=.236, S D=.121)$;

$341\left(t(2,47)=4.40, p<.001 ; \mathrm{BF}_{10}=360.77\right.$, Figure 3D).

A

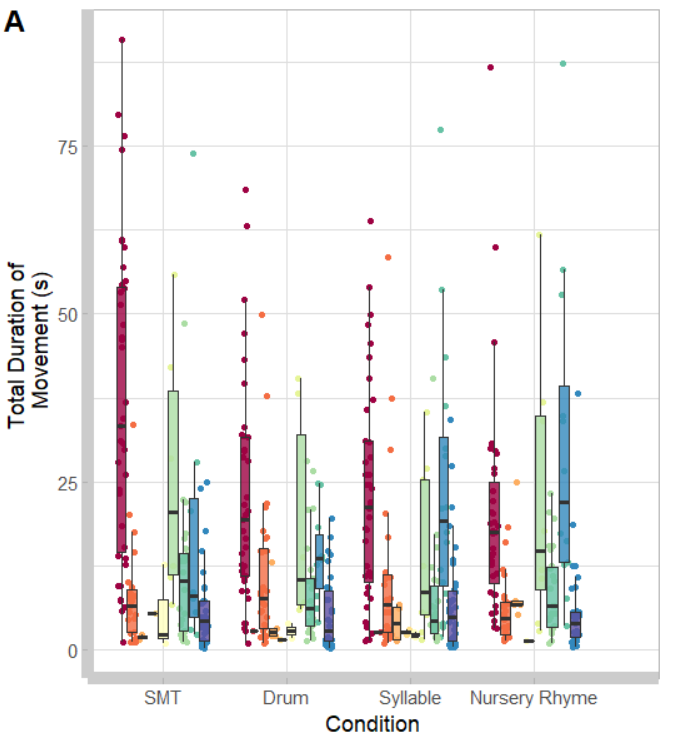

C
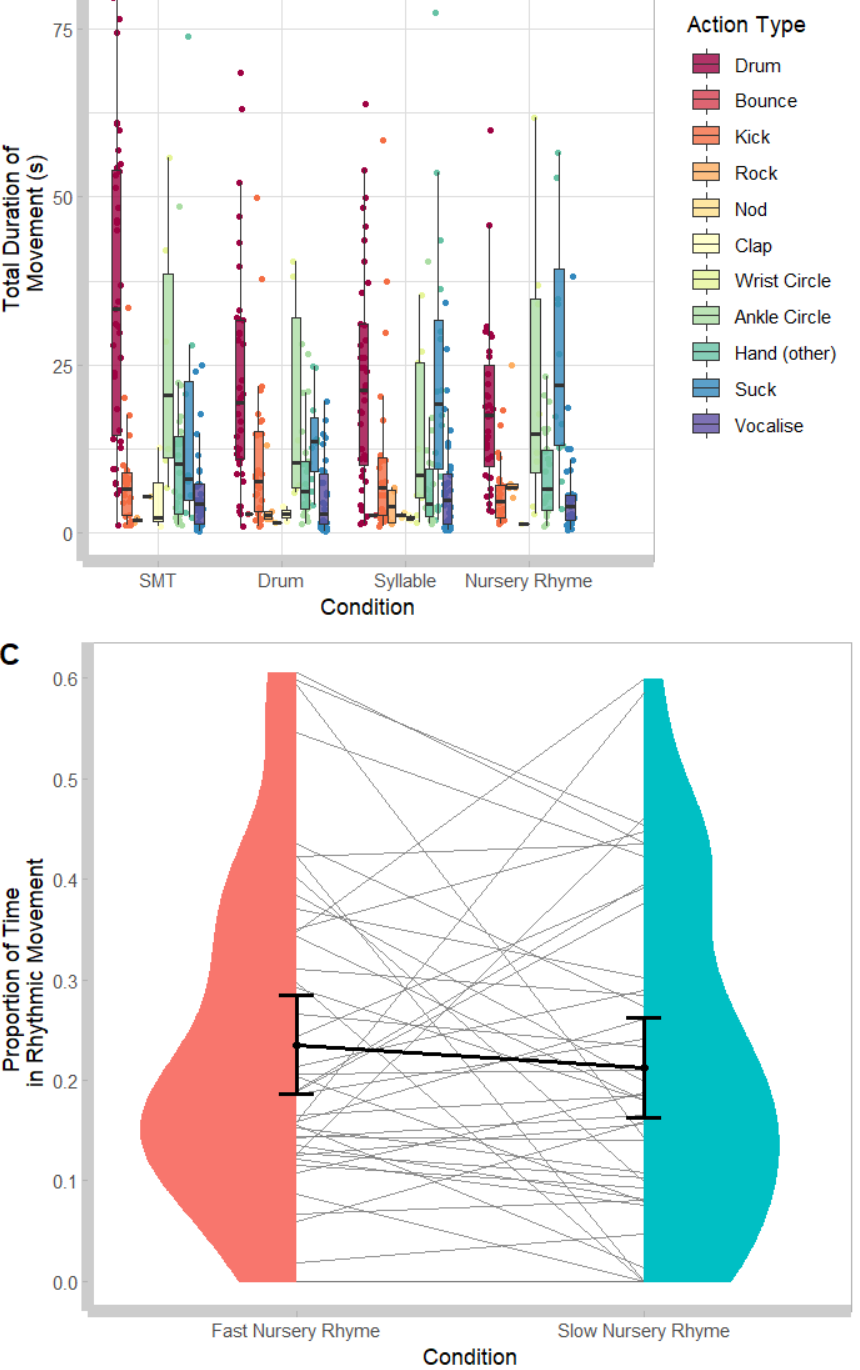

Action Type

Bounce

Nod

, Clap

Hand (other)

Vocalise
B

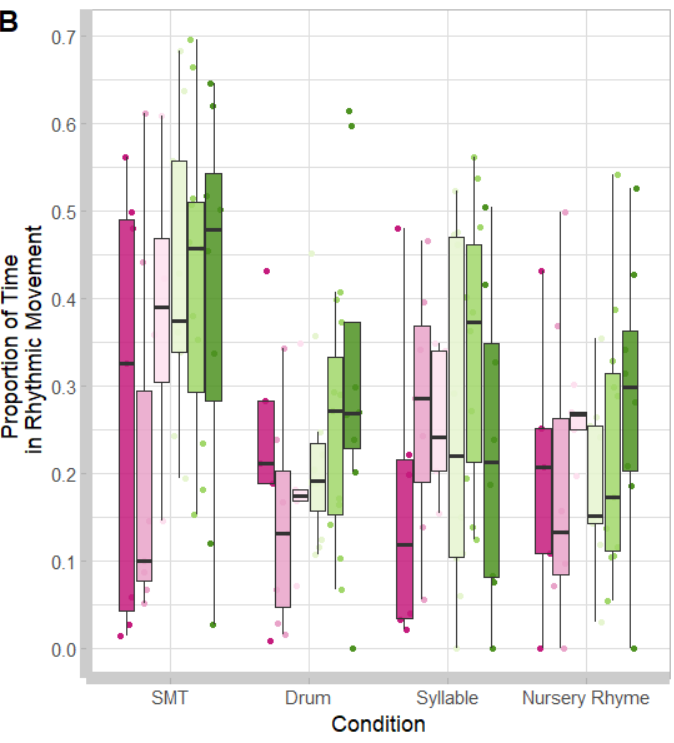

D

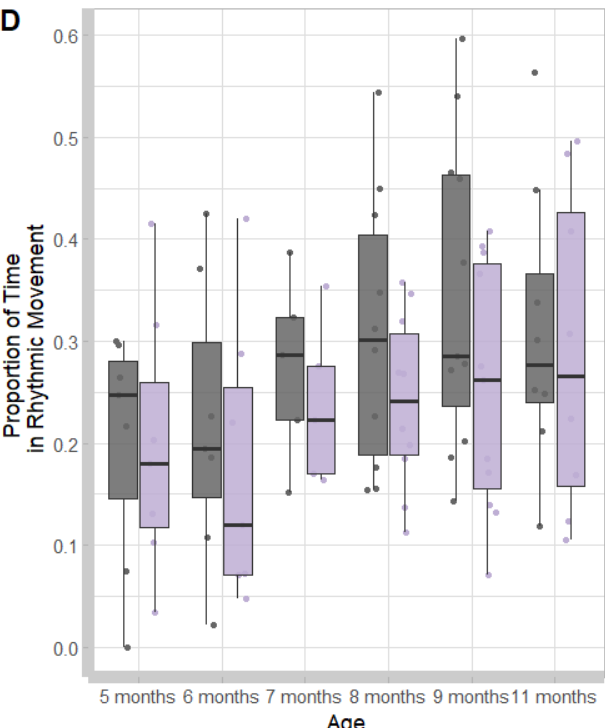

Trial Type

Partner Not
Drumming/Singing

Partner
Drumming/Singing 
344 Figure 3A. Total duration of rhythmic movements by movement type, by condition. Note:

345 Movements could be performed concurrently (e.g. drumming and kicking). Figure 3B.

346 Proportion of time spent in rhythmic movement by age and condition. Figure 3C. Proportion

347 of time spent in rhythmic movement in Slow $(1 \mathrm{~Hz})$ and Fast $(\sim 2 \mathrm{~Hz})$ Nursery Rhymes.

348 Group level Means and $\mathrm{Cl}$ are shown in bold, and individual data points are connected. Half

349 violins show the distribution of results. Figure 3D. Proportion of time spent in rhythmic

350 movement by whether the experimenter was drumming or singing along with the pre-

351 recorded video stimuli. 
352

353

354

355

356

357

358

359

360

361

362

363

364

365

366

367

368

369

370

371

372

373

374

375

376

\section{Discussion}

Here we explored infants' ability to generate motor rhythms and couple them to external acoustic speech (syllable, nursery rhyme) and non-speech (drumbeat) rhythms. Importantly, we also measured infants' natural rate of rhythmic movement in the absence of stimuli (SMT) to contextualise the development of sensorimotor synchronisation (SMS). Through novel longitudinal measurements, we show that infants' rhythmic movement becomes faster and more regular with development. We also show, for the first time, developmental change in the ability of infants to adapt their movements in response to auditory stimuli over the first year of life. Particularly, by 11-months infants were decelerating from their SMT to better match the rate of slow nursery rhymes. Accordingly, behavioural markers of rhythm development can be identified within the first year of life. Individual differences in these measures can potentially be used in future work to identify those at risk of poorer language outcomes.

The updated TSF (Goswami, 2018) predicts that SMS around a beat rate of $2 \mathrm{~Hz}$ could be developmentally important. Infant SMT indeed increased towards a $\sim 2 \mathrm{~Hz}$ tempo over time, a pattern mirrored when infants were exposed to a $2 \mathrm{~Hz}$ drum beat or repeated syllable. Critically, in the Nursery Rhyme condition, older infants adapted to the slower sung tempi. Given established difficulties in deceleration through childhood (Bobin-Begue \& Provasi, 2008; McAuley et al., 2006), it is particularly noteworthy that at 11-months approximately half our sample showed deceleration from SMT when drumming with slow nursery rhymes. Change from SMT to slow rhythms may provide a critical index of early sensorimotor synchronisation ability. We did not find differences in periodicity or tempo matching between the repeated drum beat and repeated syllable conditions. The presence of a strong beat in both conditions apparently ameliorated potential effects of increased complexity regarding the repeated 'ta' sound, which had a longer and more variable 
377 amplitude rise time than the drumbeat. This increased linguistic complexity did not affect

378 infant matching of their rate of movement.

Overall, infant drumming showed a significant increase in regularity with

development. Infant actions were more variable when the infant was attempting sensorimotor synchronisation than when producing an internally generated rhythm, as regularity was greater in silence than during auditory stimulation. However, gains in regularity were not as pronounced in the linguistic conditions. A similar rate of drumming but diverging variability across the Drum and Syllable conditions may indicate that rather than temporal matching per se, infants struggle with consistency of responding. Consistency is an important indicator for children with dyslexia, who are significantly more variable than typically-developing controls in tapping to a $2 \mathrm{~Hz}$ metronome beat (Thomson \& Goswami, 2008). Regularity of drumming did not increase in the Nursery Rhyme condition, despite infants being better able to decelerate from their SMT with age. Indeed, at 11-months, infants who were drumming more slowly also showed greater variability. As we follow up these infants' language development, the possible importance of consistency, deceleration and regularity regarding individual differences may be revealed.

Qualitative analyses indicated that the differences found across conditions were unlikely to be due to a differential level of engagement. Infants exhibited an equal level of rhythmic movements in the most complex Nursery Rhyme condition and the simplest Drum condition. However, the generalizability of our findings may depend on the different kinds of stimulation compared. While similar infant data could be expected across languages for drumbeats and syllables, the Nursery Rhyme condition may prove an exception. The qualitative analyses also showed that infants moved more when the adult experimenter was not drumming/singing along with the stimuli. Whilst a social partner is beneficial for achieving synchrony in toddlerhood (Kirschner \& Tomasello, 2009), infants inhibit dance behaviours in the presence of a partner (Rocha \& Mareschal, 2017). Hence there may be different 
motivations for interpersonal versus sensorimotor synchronisation and this may also affect generalizability.

As our infants age, our individual differences approach will allow one of the core tenets of the TSF to be tested. The infants enrolled in the current study are being followed to 2.5 years-of-age, participating in a battery of language tasks measuring phonological awareness, grammar, speech timing, and vocabulary. Our ongoing work will use the data in the current report to feed into models of language outcome, which may contribute vital knowledge regarding developmental pathways towards successful language acquisition. Whilst in this case SMS was measured using Motion Capture, which requires specialist equipment, the same analyses can be applied to 2D video data using Al technology, or even by measuring the sound signal produced by the drumming infant (e.g. Rocha et al., 2021). The current data can therefore provide distinct added value to neural measures in finding behavioural markers that are suitable for large scale, low cost, screening for intervention.

In conclusion, our current findings characterise the typical development of spontaneous motor tempo and infant sensorimotor synchronisation over the first year of life. We find that prior to their first birthday, infants' rhythm production becomes faster and more regular, and that infants become better able to adapt their tempo towards the rate of external auditory stimulation. We further show that by the end of the first year, more complex linguistic stimuli are met with more variable infant behaviour. This is potentially developmentally important, given that rhythmic linguistic routines characterise nursery settings in many cultures and are thought to benefit language development. In future analyses with our sample, we can extend our SMS findings to identify which are early markers of successful and less successful language acquisition. Measurement of sensorimotor synchronisation, in contrast to neural measures, is a cheap, accessible, and sustainable platform that may identify those at risk of disordered language development. 
428 Accordingly, the current study has potentially far-reaching implications for both theory and 429 practise.

References

434 Attaheri, A., Choisdealbha, Á. N., Di Liberto, G. M., Rocha, S., Brusini, P., Mead, N., ... \& 435 Goswami, U. (2022). Delta-and theta-band cortical tracking and phase-amplitude coupling to 436 sung speech by infants. Neurolmage, 247, 118698.

437 https://doi.org/10.1016/j.neuroimage.2021.118698

Bates, D., Mächler, M., Bolker, B., \& Walker, S. (2015). "Fitting Linear Mixed-Effects Models

Using Ime4." Journal of Statistical Software, 67(1), 1-48.

https://doi.org/10.18637/jss.v067.i01

Bhide, A., Power, A., \& Goswami, U. (2013). A Rhythmic Musical Intervention for Poor

Readers: A Comparison of Efficacy With a Letter-Based Intervention. Mind, Brain, and

445 Education, 7(2), 113-123. https://doi.org/10.1111/mbe.12016

447 Bobin-Bègue, A., Provasi, J., Marks, A., \& Pouthas, V. (2006). Influence of auditory tempo

448 on the endogenous rhythm of non-nutritive sucking. European Review of Applied

449 Psychology, 56(4), 239-245. https://doi.org/10.1016/j.erap.2005.09.006 
451 Bobin-Bègue, Anne, \& Provasi, J. (2008). Régulation rythmique avant 4 ans: Effet d'un 452 tempo auditif sur le tempo moteur. Annee Psychologique. https://hal.archives-ouvertes.fr/hal-

453

454

455

456

457

458

459

460

461

462

463

464

465

466

467

468

469

470

471

472

473

474 02887838

Burger, B., \& Toiviainen, P. (2013). MoCap Toolbox - A Matlab toolbox for computational analysis of movement data. In R. Bresin (Ed.), Proceedings of the Sound and Music Computing Conference 2013, SMC 2013, Logos Verlag Berlin, Stockholm, Sweden (pp. 172178). Berlin: Logos Verlag Berlin.

Carr, K. W., White-Schwoch, T., Tierney, A. T., Strait, D. L., \& Kraus, N. (2014). Beat synchronization predicts neural speech encoding and reading readiness in preschoolers. Proceedings of the National Academy of Sciences, 111(40), 14559-14564. https://doi.org/10.1073/pnas.1406219111

Corriveau, K. H., \& Goswami, U. (2009). Rhythmic motor entrainment in children with speech and language impairments: Tapping to the beat. Cortex, 45(1), 119-130. https://doi.org/10.1016/j.cortex.2007.09.008

Cumming, R., Wilson, A., Leong, V., Colling, L. J., \& Goswami, U. (2015). Awareness of Rhythm Patterns in Speech and Music in Children with Specific Language Impairments. Frontiers in Human Neuroscience, 9. https://doi.org/10.3389/fnhum.2015.00672 phonetics, 11(1), 51-62. https://doi.org/10.1016/S0095-4470(19)30776-4 
476 de l'Etoile, S. K., Bennett, C., \& Zopluoglu, C. (2020). Infant Movement Response to

477 Auditory Rhythm. Perceptual and Motor Skills, 127(4), 651-670.

478 https://doi.org/10.1177/0031512520922642

479

480 Degé, F., \& Schwarzer, G. (2011). The Effect of a Music Program on Phonological

481 Awareness in Preschoolers. Frontiers in Psychology, 2.

482 https://doi.org/10.3389/fpsyg.2011.00124

483

484 Drake, C., Jones, M. R., \& Baruch, C. (2000). The development of rhythmic attending in 485 auditory sequences: Attunement, referent period, focal attending. Cognition, 77(3), 251-288.

486 https://doi.org/10.1016/S0010-0277(00)00106-2

487

488 Falk, S., Müller, T., \& Dalla Bella, S. (2015). Non-verbal sensorimotor timing deficits in children and adolescents who stutter. Frontiers in Psychology, 6.

490 https://doi.org/10.3389/fpsyg.2015.00847

491

492 Flaugnacco, E., Lopez, L., Terribili, C., Zoia, S., Buda, S., Tilli, S., Monasta, L., Montico, M., 493 Sila, A., Ronfani, L., \& Schön, D. (2014). Rhythm perception and production predict reading 494 abilities in developmental dyslexia. Frontiers in Human Neuroscience, 8.

495 https://doi.org/10.3389/fnhum.2014.00392 
497 Fujii, S., Watanabe, H., Oohashi, H., Hirashima, M., Nozaki, D., \& Taga, G. (2014).

498 Precursors of Dancing and Singing to Music in Three- to Four-Months-Old Infants. PLOS

499 ONE, 9(5), e97680. https://doi.org/10.1371/journal.pone.0097680

500

501 Goswami, U. (2011). A temporal sampling framework for developmental dyslexia. Trends in

502 Cognitive Sciences, 15(1), 3-10. https://doi.org/10.1016/j.tics.2010.10.001

503

504 Goswami, U. (2018). A Neural Basis for Phonological Awareness? An Oscillatory Temporal-

505 Sampling Perspective. Current Directions in Psychological Science, 27(1), 56-63.

506 https://doi.org/10.1177/0963721417727520

507

508 Harris, P. A., Taylor, R., Thielke, R., Payne, J., Gonzalez, N., \& Conde, J. G. (2009).

509 Research electronic data capture (REDCap)—a metadata-driven methodology and workflow

510 process for providing translational research informatics support. Journal of biomedical

511 informatics, 42(2), 377-381. https://doi.org/10.1016/j.jbi.2008.08.010

512

513 Kirschner, S., \& Tomasello, M. (2009). Joint drumming: Social context facilitates

514

synchronization in preschool children. Journal of Experimental Child Psychology, 102(3),

515

299-314. https://doi.org/10.1016/j.jecp.2008.07.005

516

517 Kuznetsova, A., Brockhoff, P. \& Christensen, R. (2017). "ImerTest Package: Tests in Linear

518 Mixed Effects Models." Journal of Statistical Software, 82(13), 1-26.

519 https://doi.org/10.18637/jss.v082.i13 
521 Ladányi, E., Persici, V., Fiveash, A., Tillmann, B., \& Gordon, R. L. (2020). Is atypical rhythm

522 a risk factor for developmental speech and language disorders? WIREs Cognitive Science,

523 11(5), e1528. https://doi.org/10.1002/wcs.1528

524

525 Lee, H.-Y., Sie, Y.-S., Chen, S.-C., \& Cheng, M.-C. (2015). The Music Perception

526 Performance of Children with and without Dyslexia in Taiwan. Psychological Reports,

527 116(1), 13-22. https://doi.org/10.2466/15.28.PR0.116k15w8

528

529 Leong, V., Kalashnikova, M., Burnham, D., \& Goswami, U. (2017). The Temporal Modulation

530 Structure of Infant-Directed Speech. Open Mind, 1(2), 78-90.

531 https://doi.org/10.1162/OPMI_a_00008

532

533

Linnavalli, T., Putkinen, V., Lipsanen, J., Huotilainen, M., \& Tervaniemi, M. (2018). Music

534

playschool enhances children's linguistic skills. Scientific Reports, 8(1), 8767.

535

https://doi.org/10.1038/s41598-018-27126-5

536

537

Lundetræ, K., \& Thomson, J. M. (2018). Rhythm production at school entry as a predictor of poor reading and spelling at the end of first grade. Reading and Writing, 31(1), 215-237. https://doi.org/10.1007/s11145-017-9782-9

541 McAuley, J. D., Jones, M. R., Holub, S., Johnston, H. M., \& Miller, N. S. (2006). The time of

542 our lives: Life span development of timing and event tracking. Journal of Experimental

543 Psychology: General, 135(3), 348-367. https://doi.org/10.1037/0096-3445.135.3.348 
545 Olander, L., Smith, A., \& Zelaznik, H. N. (2010). Evidence That a Motor Timing Deficit Is a

546 Factor in the Development of Stuttering. Journal of Speech, Language, and Hearing

547 Research, 53(4), 876-886. https://doi.org/10.1044/1092-4388(2009/09-0007)

548

549 Overy, K., Nicolson, R. I., Fawcett, A. J., \& Clarke, E. F. (2003). Dyslexia and music:

550 Measuring musical timing skills. Dyslexia, 9(1), 18-36. https://doi.org/10.1002/dys.233

551

552 Persici, V., Stucchi, N., \& Arosio, F. (2018, December). Rhythmic and Morphosyntactic

553 predictions: The anticipation skills of Italian children with developmental dyslexia. In 15th

554 Conference of the Italian Association for Cognitive Sciences.

555

556

557 Politimou, N., Dalla Bella, S., Farrugia, N., \& Franco, F. (2019). Born to Speak and Sing:

558 Musical Predictors of Language Development in Pre-schoolers. Frontiers in Psychology, 10.

559 https://doi.org/10.3389/fpsyg.2019.00948

560

561 Rios-Lopez, P., Molinaro, N., \& Lallier, M. (2019). Tapping to a beat in synchrony predicts

562 brain print sensitivity in pre-readers. Brain \& Language, 199, 104693.

563 doi.org/10.1016/j.bandl.2019.104693

564

565 Rocha, S., \& Mareschal, D. (2017). Getting into the Groove: The Development of Tempo-

566 Flexibility Between 10 and 18 Months of Age. Infancy, 22(4), 540-551.

567 https://doi.org/10.1111/infa.12169 
569 Rocha, S., Southgate, V., \& Mareschal, D. (2021). Infant Spontaneous Motor Tempo.

570 Developmental Science, 24(2), e13032. https://doi.org/10.1111/desc.13032

571

572 Rocha, S., Attaheri, A., Ní Choisdealbha, Á., Brusini, P., Flanagan, S. A., Mead, N., ...

573 Goswami, U. (2021). Infant sensorimotor synchronisation to speech and non-speech

574 rhythms: A longitudinal study. PsyArxiv. https://doi.org/10.31234/osf.io/jbrga

575

576 Sloetjes, H., \& Wittenburg, P. (2008). Annotation by category - ELAN and ISO DCR. In:

577 Proceedings of the 6th International Conference on Language Resources and Evaluation

578 (LREC 2008).

579

580 Thelen, E. (1981). Kicking, rocking, and waving: Contextual analysis of rhythmical

581 stereotypies in normal human infants. Animal Behaviour, 29(1), 3-11.

582 https://doi.org/10.1016/S0003-3472(81)80146-7

583

584 Thompson, E. C., White-Schwoch, T., Tierney, A., \& Kraus, N. (2015). Beat Synchronization across the Lifespan: Intersection of Development and Musical Experience. PLOS ONE,

586 10(6), e0128839. https://doi.org/10.1371/journal.pone.0128839

587

588

Thomson, J. M., \& Goswami, U. (2008). Rhythmic processing in children with developmental

589 dyslexia: Auditory and motor rhythms link to reading and spelling. Journal of Physiology-

590 Paris, 102(1), 120-129. https://doi.org/10.1016/j.jphysparis.2008.03.007 
592 Tierney, A., \& Kraus, N. (2014). Auditory-motor entrainment and phonological skills: Precise

593 auditory timing hypothesis (PATH). Frontiers in Human Neuroscience, 8.

594 https://doi.org/10.3389/fnhum.2014.00949

595

596 Trehub, S. E., \& Trainor, L. (1998). Singing to infants: Lullabies and play songs. In C. Rovee-

597 Collier, L. Lipsitt \& H. Hayne (Eds.), Advances in infancy research (Vol. 12) (pp. 43-77).

598 Ablex

599

600 Zentner, M., \& Eerola, T. (2010). Rhythmic engagement with music in infancy. Proceedings

601 of the National Academy of Sciences, 107(13), 5768-5773.

602 https://doi.org/10.1073/pnas.1000121107

603

604 Supplementary Materials

605 Table S1 Number and age in days of infants who provided data at each time point

\begin{tabular}{lll}
\hline Time Point & N & Mean Age Days (Min - Max) \\
\hline 5 months & 65 & $144(134-155)$ \\
6 months & 67 & $186(165-201)$ \\
7 months & 68 & $214(209-229)$ \\
8 months & 74 & $242(232-256)$ \\
9 months & 82 & $270(265-283)$ \\
11 months & 87 & $333(325-350)$ \\
\hline
\end{tabular}

606

607 


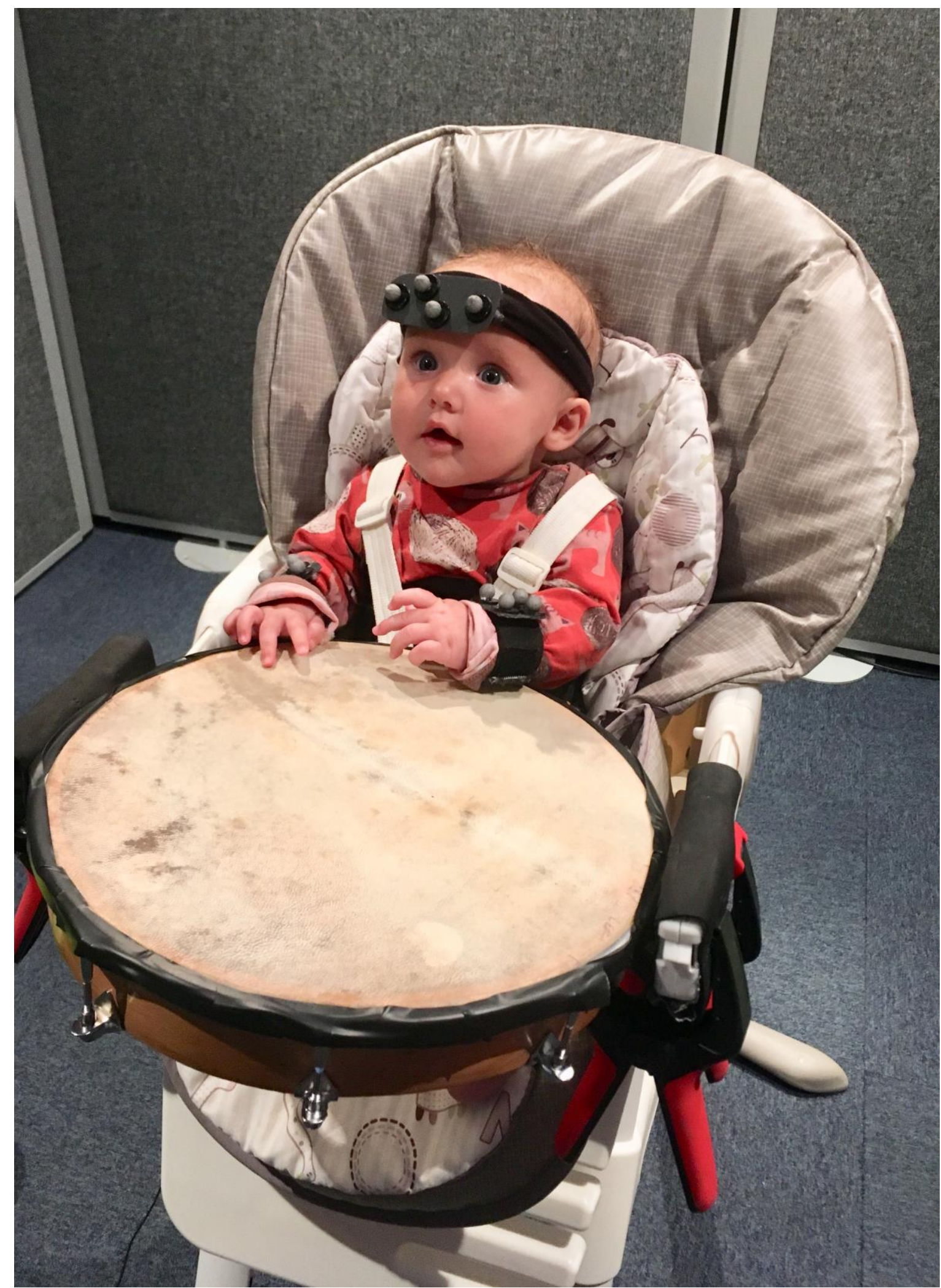

Figure S1. Photograph of infant seated in adapted highchair with drum attachment, with head and wrist reflective markers visible. 
611 Table S2 Details of Nursery Rhyme stimuli (NB. IOI calculated as the average distance in 612 milliseconds between p-centres of each stress syllable)

\begin{tabular}{lllll}
\hline Rhyme & Rate $(\mathrm{Hz})$ & IOI $(\mathrm{ms})$ & Presentation Order & Slow/Fast \\
\hline Mary Had a Little Lamb (verse 1) & 1 & 1000 & 3 & Slow \\
Mary Had a Little Lamb (verse 2) & 1 & 1000 & 4 & Slow \\
Mary Had a Little Lamb (verse 3) & 1 & 1000 & 5 & Slow \\
Incy Wincy Spider & 1.82 & 550 & 2 & Fast \\
Sing a Song of Sixpence & 1.89 & 530 & 7 & Fast \\
Twinkle Twinkle Little Star & 2 & 500 & 8 & Fast \\
Frere Jacque & 2.13 & 470 & 1 & Fast \\
Simple Simon & 2.33 & 430 & 6 & Fast \\
\hline
\end{tabular}

613 
Table S3 Behavioural coding scheme

\begin{tabular}{ll}
\hline Behaviour & Criteria \\
\hline Drumming & $\begin{array}{l}\text { Vertical arm movements, does not need to make contact with } \\
\text { the drum }\end{array}$ \\
Bouncing & $\begin{array}{l}\text { Lengthens and contracts torso in vertical motion } \\
\text { Kicking }\end{array}$ \\
Rocking/Swaying & Moves torso left to right or forward and backward, does not \\
& include up and down motion \\
Nodding & Moves head on a single plane in any direction \\
Clapping & Claps palms of hands together \\
Wrist circle & Circles hand in any direction from wrist \\
Ankle circle & Circles foot in any direction from ankle \\
Hand other & Other repetitive movements of the hand e.g. scratching the \\
Sucking & drum \\
\hline
\end{tabular}

617 
619 Table S4 Table of coefficients for linear mixed effect models

\begin{tabular}{|c|c|c|c|c|c|c|c|c|c|}
\hline \multirow[b]{2}{*}{ Predictors } & \multicolumn{3}{|c|}{ Tempo Mismatch } & \multicolumn{2}{|c|}{ Periodicity } & \multicolumn{3}{|c|}{ Regularity } & \multirow[b]{2}{*}{$p$} \\
\hline & $\begin{array}{c}\text { Estimat } \\
\text { es }\end{array}$ & $\mathrm{Cl}$ & $p$ & Estimates & $\mathrm{Cl}$ & $p$ & $\begin{array}{c}\text { Estimat } \\
\text { es }\end{array}$ & $\mathrm{Cl}$ & \\
\hline (Intercept) & $\begin{array}{c}279.1 \\
2\end{array}$ & $\begin{array}{c}251.26 \\
-306.9 \\
7\end{array}$ & $\begin{array}{c}<0.00 \\
1\end{array}$ & $\begin{array}{c}645.6 \\
5\end{array}$ & $\begin{array}{c}603.16 \\
-688.1 \\
4\end{array}$ & $\begin{array}{c}<0.00 \\
1\end{array}$ & 0.50 & $\begin{array}{c}0.48- \\
0.53\end{array}$ & $<0.001$ \\
\hline $\begin{array}{l}\text { condition } \\
\text { [drum] }\end{array}$ & -0.33 & $\begin{array}{c}- \\
36.67- \\
36.01\end{array}$ & 0.986 & -1.81 & $\begin{array}{c}- \\
49.38- \\
45.75\end{array}$ & 0.941 & -0.04 & $\begin{array}{c}- \\
0.07-- \\
0.00\end{array}$ & 0.024 \\
\hline condition [ta] & -12.05 & $\begin{array}{c}- \\
52.22- \\
28.12\end{array}$ & 0.557 & 5.99 & $\begin{array}{c}- \\
46.86- \\
58.84\end{array}$ & 0.824 & -0.02 & $\begin{array}{c}- \\
0.05- \\
0.01\end{array}$ & 0.226 \\
\hline condition [nr] & 16.73 & $\begin{array}{c}- \\
18.56- \\
52.01\end{array}$ & 0.353 & -21.94 & $\begin{array}{c}- \\
67.93- \\
24.06\end{array}$ & 0.350 & -0.02 & $\begin{array}{c}- \\
0.05- \\
0.01\end{array}$ & 0.111 \\
\hline timepoint [6] & -97.59 & $\begin{array}{c}- \\
135.35 \\
-- \\
59.83\end{array}$ & $\begin{array}{c}<0.00 \\
1\end{array}$ & -48.26 & $\begin{array}{c}- \\
103.94 \\
-7.42\end{array}$ & 0.089 & 0.08 & $\begin{array}{c}0.04- \\
0.11\end{array}$ & $<0.001$ \\
\hline timepoint [7] & $\begin{array}{c}- \\
105.7 \\
1\end{array}$ & $\begin{array}{c}- \\
143.20 \\
-- \\
68.21\end{array}$ & $\begin{array}{c}<0.00 \\
1\end{array}$ & -90.60 & $\begin{array}{c}- \\
145.14 \\
-- \\
36.06\end{array}$ & 0.001 & 0.08 & $\begin{array}{c}0.05- \\
0.11\end{array}$ & $<0.001$ \\
\hline timepoint [8] & $\begin{array}{c}- \\
125.0 \\
0\end{array}$ & $\begin{array}{c}- \\
160.59 \\
-- \\
89.41\end{array}$ & $\begin{array}{c}<0.00 \\
1\end{array}$ & $\begin{array}{c}- \\
125.1 \\
0\end{array}$ & $\begin{array}{c}- \\
181.73 \\
-- \\
68.47\end{array}$ & $\begin{array}{c}<0.00 \\
1\end{array}$ & 0.11 & $\begin{array}{c}0.07- \\
0.14\end{array}$ & $<0.001$ \\
\hline timepoint [9] & $\begin{array}{c}- \\
125.2 \\
0\end{array}$ & $\begin{array}{c}- \\
160.04 \\
-- \\
90.35\end{array}$ & $\begin{array}{c}<0.00 \\
1\end{array}$ & $\begin{array}{c}- \\
106.5 \\
5\end{array}$ & $\begin{array}{c}- \\
160.46 \\
-- \\
52.64\end{array}$ & $\begin{array}{c}<0.00 \\
1\end{array}$ & 0.11 & $\begin{array}{c}0.08- \\
0.14\end{array}$ & $<0.001$ \\
\hline timepoint [11] & $\begin{array}{c}- \\
110.8 \\
0\end{array}$ & $\begin{array}{c}- \\
147.04 \\
-- \\
74.56\end{array}$ & $\begin{array}{c}<0.00 \\
1\end{array}$ & $\begin{array}{c}- \\
111.1 \\
0\end{array}$ & $\begin{array}{c}- \\
168.90 \\
-- \\
53.30\end{array}$ & $\begin{array}{c}<0.00 \\
1\end{array}$ & 0.12 & $\begin{array}{c}0.08- \\
0.15\end{array}$ & $<0.001$ \\
\hline $\begin{array}{l}\text { condition } \\
\text { [drum] }{ }^{*} \\
\text { timepoint [6] }\end{array}$ & 40.91 & $\begin{array}{c}- \\
9.78- \\
91.61\end{array}$ & 0.114 & 11.13 & $\begin{array}{c}- \\
55.17- \\
77.44\end{array}$ & 0.742 & -0.03 & $\begin{array}{c}- \\
0.07- \\
0.01\end{array}$ & 0.162 \\
\hline
\end{tabular}




\begin{tabular}{|c|c|c|c|c|c|c|c|c|c|}
\hline $\begin{array}{l}\text { condition [ta] } \\
\text { * } \\
\text { timepoint [6] }\end{array}$ & 43.15 & $\begin{array}{c}- \\
11.41- \\
97.71\end{array}$ & 0.121 & -22.19 & $\begin{array}{c}- \\
93.83- \\
49.45\end{array}$ & 0.544 & 0.01 & $\begin{array}{c}- \\
0.04- \\
0.05\end{array}$ & 0.812 \\
\hline $\begin{array}{l}\text { condition [nr] } \\
\text { * } \\
\text { timepoint [6] }\end{array}$ & 93.57 & $\begin{array}{r}44.51- \\
142.62\end{array}$ & $\begin{array}{c}<0.00 \\
1\end{array}$ & 23.78 & $\begin{array}{c}- \\
40.16- \\
87.71\end{array}$ & 0.466 & 0.00 & $\begin{array}{c}- \\
0.04- \\
0.05\end{array}$ & 0.817 \\
\hline $\begin{array}{l}\text { condition } \\
\text { [drum] }^{*} \\
\text { timepoint [7] }\end{array}$ & 36.23 & $\begin{array}{c}- \\
13.07- \\
85.52\end{array}$ & 0.150 & 3.47 & $\begin{array}{c}- \\
60.91- \\
67.85\end{array}$ & 0.916 & 0.01 & $\begin{array}{c}- \\
0.03- \\
0.05\end{array}$ & 0.675 \\
\hline $\begin{array}{l}\text { condition [ta] } \\
\text { * } \\
\text { timepoint [7] }\end{array}$ & 45.74 & $\begin{array}{c}- \\
6.76- \\
98.23\end{array}$ & 0.088 & 8.57 & $\begin{array}{c}- \\
60.20- \\
77.34\end{array}$ & 0.807 & 0.01 & $\begin{array}{c}- \\
0.04- \\
0.05\end{array}$ & 0.688 \\
\hline $\begin{array}{l}\text { condition [nr] } \\
\text { * } \\
\text { timepoint [7] }\end{array}$ & $\begin{array}{c}105.2 \\
5\end{array}$ & $\begin{array}{r}56.62- \\
153.89\end{array}$ & $\begin{array}{c}<0.00 \\
1\end{array}$ & 48.80 & $\begin{array}{c}- \\
14.57- \\
112.16\end{array}$ & 0.131 & 0.01 & $\begin{array}{c}- \\
0.03- \\
0.05\end{array}$ & 0.564 \\
\hline $\begin{array}{l}\text { condition } \\
\text { [drum] }^{*} \\
\text { timepoint [8] }^{\text {ime }}\end{array}$ & 51.72 & $\begin{array}{l}3.68- \\
99.77\end{array}$ & 0.035 & 19.89 & $\begin{array}{c}- \\
42.87- \\
82.65\end{array}$ & 0.535 & -0.00 & $\begin{array}{c}- \\
0.05- \\
0.04\end{array}$ & 0.812 \\
\hline $\begin{array}{l}\text { condition [ta] } \\
\text { timepoint [8] }\end{array}$ & 59.46 & $\begin{array}{l}8.06- \\
110.87\end{array}$ & 0.023 & 20.41 & $\begin{array}{c}- \\
47.02- \\
87.83\end{array}$ & 0.553 & -0.03 & $\begin{array}{c}- \\
0.07- \\
0.01\end{array}$ & 0.167 \\
\hline $\begin{array}{l}\text { condition [nr] } \\
\text { * } \\
\text { timepoint [8] }\end{array}$ & $\begin{array}{c}137.4 \\
3\end{array}$ & $\begin{array}{r}90.26- \\
184.60\end{array}$ & $\begin{array}{c}<0.00 \\
1\end{array}$ & 55.76 & $\begin{array}{l}- \\
5.71- \\
117.23\end{array}$ & 0.075 & -0.03 & $\begin{array}{c}- \\
0.07- \\
0.01\end{array}$ & 0.153 \\
\hline $\begin{array}{l}\text { condition } \\
\text { [drum] * }^{*} \\
\text { timepoint [9] }\end{array}$ & 46.84 & $\begin{array}{c}- \\
0.61- \\
94.28\end{array}$ & 0.053 & 11.50 & $\begin{array}{c}- \\
50.51- \\
73.52\end{array}$ & 0.716 & -0.00 & $\begin{array}{c}- \\
0.04- \\
0.04\end{array}$ & 0.875 \\
\hline $\begin{array}{l}\text { condition [ta] } \\
{ }_{*} \\
\text { timepoint [9] }\end{array}$ & 64.77 & $\begin{array}{r}13.87- \\
115.67\end{array}$ & 0.013 & 16.32 & $\begin{array}{c}- \\
50.46- \\
83.11\end{array}$ & 0.632 & -0.02 & $\begin{array}{c}- \\
0.06- \\
0.02\end{array}$ & 0.347 \\
\hline $\begin{array}{l}\text { condition [nr] } \\
\text { * } \\
\text { timepoint [9] }\end{array}$ & $\begin{array}{c}154.0 \\
4\end{array}$ & $\begin{array}{c}107.60 \\
-200.4 \\
7\end{array}$ & $\begin{array}{c}<0.00 \\
1\end{array}$ & 59.52 & $\begin{array}{l}- \\
0.99- \\
120.03\end{array}$ & 0.054 & -0.04 & $\begin{array}{c}- \\
0.08-- \\
0.00\end{array}$ & 0.044 \\
\hline $\begin{array}{l}\text { condition } \\
\text { [drum] }^{*} \\
\text { timepoint [11] }^{\text {[1 }}\end{array}$ & 28.37 & $\begin{array}{c}- \\
18.84- \\
75.59\end{array}$ & 0.239 & 7.51 & $\begin{array}{c}- \\
54.22- \\
69.24\end{array}$ & 0.812 & 0.01 & $\begin{array}{c}- \\
0.03- \\
0.05\end{array}$ & 0.668 \\
\hline $\begin{array}{l}\text { condition [ta] } \\
\text { t } \\
\text { timepoint [11] }\end{array}$ & 59.10 & $\begin{array}{l}8.61- \\
109.60\end{array}$ & 0.022 & 20.30 & $\begin{array}{c}- \\
45.94- \\
86.54\end{array}$ & 0.548 & -0.04 & $\begin{array}{c}- \\
0.09- \\
0.00\end{array}$ & 0.051 \\
\hline
\end{tabular}




$\begin{array}{lccccccccc}\text { condition [nr] } & 149.2 & 102.38 & <0.00 & 87.56 & 26.41- & \mathbf{0 . 0 0 5} & -0.07 & - & <0.001 \\ * & 4 & -196.1 & \mathbf{1} & & 148.72 & & & 0.11-- & \\ \text { timepoint [11] } & & 0 & & & & & & 0.03\end{array}$

\section{Random Effects}

\begin{tabular}{|c|c|c|c|}
\hline$\sigma^{2}$ & 9119.13 & 15455.45 & 0.01 \\
\hline $\mathrm{T}_{00}$ & 2556.54 filename & 12157.84 filename & 0.00 filename \\
\hline \multirow[t]{5}{*}{$\mathrm{T}_{11}$} & 3915.65 filename.timepoint6 & $\begin{array}{l}17759.63 \text { filename.tim } \\
\text { epoint6 }\end{array}$ & 0.00 filename.timepoint6 \\
\hline & 4017.61 filename.timepoint7 & $\begin{array}{l}16813.11 \text { filename.tim } \\
\text { epoint7 }\end{array}$ & 0.01 filename.timepoint7 \\
\hline & 2515.78 filename.timepoint8 & $\begin{array}{l}24053.45 \text { filename.tim } \\
\text { epoint8 }\end{array}$ & 0.01 filename.timepoint8 \\
\hline & 1938.65 filename.timepoint9 & $\begin{array}{l}18939.20 \text { filename.tim } \\
\text { epoint9 }\end{array}$ & 0.01 filename.timepoint9 \\
\hline & 4481.56 filename.timepoint11 & $\begin{array}{l}29139.85 \text { filename.tim } \\
\text { epoint11 }\end{array}$ & 0.01 filename.timepoint11 \\
\hline \multirow[t]{5}{*}{$\rho_{01}$} & -0.75 & -0.79 & 0.13 \\
\hline & -0.66 & -0.82 & -0.11 \\
\hline & -0.77 & -0.89 & -0.15 \\
\hline & -0.56 & -0.74 & -0.16 \\
\hline & -0.78 & -0.82 & -0.08 \\
\hline ICC & 0.17 & & 0.47 \\
\hline $\mathrm{N}$ & 100 filename & 100 filename & 100 filename \\
\hline Observations & 1537 & 1537 & 1537 \\
\hline $\begin{array}{l}\text { Marginal } \mathrm{R}^{2} / \\
\text { Conditional } \\
\mathrm{R}^{2}\end{array}$ & $0.221 / 0.356$ & 0.073 / NA & $0.110 / 0.525$ \\
\hline
\end{tabular}


622 Table S5 Tempo Mismatch and Periodicity in milliseconds, for Slow and Fast Nursery 623 Rhymes

\begin{tabular}{lllll}
\hline & Tempo Mismatch & & Periodicity \\
Age & Slow NR (M(SD)) & Fast NR (M(SD)) & Slow NR (M(SD)) & Fast NR (M(SD)) \\
\hline 5 & $370(221)$ & $252(146)$ & $682(238)$ & $618(208)$ \\
6 & $438(183)$ & $206(126)$ & $576(194)$ & $620(147)$ \\
7 & $466(178)$ & $210(134)$ & $557(201)$ & $600(182)$ \\
8 & $471(158)$ & $219(97)$ & $575(204)$ & $555(167)$ \\
9 & $468(188)$ & $220(112)$ & $572(238)$ & $573(181)$ \\
11 & $454(160)$ & $239(139)$ & $604(231)$ & $580(208)$ \\
\hline
\end{tabular}

